\title{
Characterisation of oil sludges from different sources before treatment: high- field nuclear magnetic resonance (NMR) in the determination of oil and water content
}

Article

Accepted Version

Ramirez, D., Kowalczyk, R. M. and Collins, C. D. (2019)

Characterisation of oil sludges from different sources before treatment: high-field nuclear magnetic resonance (NMR) in the determination of oil and water content. Journal of Petroleum Science and Engineering, 174. pp. 729-737. ISSN 0920-4105 doi: https://doi.org/10.1016/j.petrol.2018.11.078 Available at https://centaur.reading.ac.uk/81029/

It is advisable to refer to the publisher's version if you intend to cite from the work. See Guidance on citing.

To link to this article DOI: http://dx.doi.org/10.1016/j.petrol.2018.11.078

Publisher: Elsevier

All outputs in CentAUR are protected by Intellectual Property Rights law, including copyright law. Copyright and IPR is retained by the creators or other copyright holders. Terms and conditions for use of this material are defined in the End User Agreement. 


\section{www.reading.ac.uk/centaur}

\section{CentAUR}

Central Archive at the University of Reading

Reading's research outputs online 


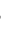

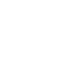

\section{determination of oil and water content}

\section{Characterisation of oil sludges from different sources before} treatment: High-field nuclear magnetic resonance (NMR) in the

Diego Ramirez $^{\text {a, }}$, Radoslaw M. Kowalczyk ${ }^{b}$, Chris D. Collins ${ }^{\text {a }}$

${ }^{\text {a }}$ Soil Research Centre, School of Archaeology, Geography and Environmental Science,

University of Reading, Whiteknights Campus, Reading RG6 6DW, United Kingdom

${ }^{\mathrm{b}}$ Chemical Analysis Facility, School of Chemistry, Food and Pharmacy, University of

Reading, P.O. Box 224, Whiteknights Campus, Reading RG6 6AD, United Kingdom

* Corresponding author: D. Ramirez

14 r.m.kowalczyk@reading.ac.uk (R. M. Kowalczyk). c.d.collins@ reading.ac.uk (C. D. Collins).

15 Declarations of interest: none.

17 Abbreviations: CPMG, Carr-Purcell-Meiboom-Gill; EPH, extractable petroleum 18 hydrocarbons; FID, free induction decay; FTIR, Fourier-transform infrared spectroscopy; GC-

19 FID, gas chromatography-flame ionisation detection; ICP-OES, inductively coupled plasma

20 optical emission spectrometry; NMR, nuclear magnetic resonance; NSC, oil refinery sludge; 
21 ODS, oil drilling sludge; PTEs, potentially toxic elements; SPE, solid-phase extraction; STS, waste engine oil sludge from gravitational settling; RS, waste engine oil sludge from centrifugation; TGA, thermogravimetric analysis; UCM, unresolved complex mixture; WSS, oil-water separator sludge.

\section{Introduction}

Approximately 60 million tons of oil sludge are accumulated by the petroleum industry each year worldwide (Hu et al., 2013); these sludges are considered to be the most substantial waste generated in this industry (Egazar'yants et al., 2015, Shen et al., 2016). In fact, it was estimated that more than one billion tons of the sludges have been stored around the world (Mirghaffari, 2017), which considerably affects the operation of the petroleum industry and have environmental impacts. The Review of the European List of Waste has classified the oil sludges as "wastes from petroleum refining, natural gas purification and pyrolytic treatment of coal" and "oil wastes and wastes of liquid fuels" (Okopol, 2008). Oil sludges are a mixture of oil hydrocarbons, water, and sediments, and are water-in-oil type (W/O) emulsions (da Silva et al., 2012, Hu et al., 2013). The sediment content of the sludges are formed from inorganic minerals in drilling fluids, storage tanks, discharges during testing and repairs of wells, accidental spills, and pipelines of the oil industry (Giles, 2010, Egazar'yants et al., 2015). Moreover, oil sludges can have metals, polyethers, and other chemicals obtained in the

41 petroleum refining ( $\mathrm{Hu}$ et al., 2013). Some metals found in oil sludges are chromium $(\mathrm{Cr})$, copper $(\mathrm{Cu})$, nickel $(\mathrm{Ni})$, lead $(\mathrm{Pb})$, vanadium $(\mathrm{V})$, and zinc $(\mathrm{Zn})$. In general, oil sludges have

43 a higher oil hydrocarbon content compared to the metal content (Hu et al., 2013). These 
potentially toxic elements (PTEs) are believed to come from oil additives (de Souza et al., 2014).

da Silva et al. (2012) reported that the composition of oil sludge is about 30 to $90 \%$ water, 4 to $7 \%$ sediments, and 5 to $60 \%$ oil. However, Saikia et al. (2003) stated that the typical composition of oil sludge is $30-50 \%$ water, $10-12 \%$ sediments and solids, $30-50 \%$ oil. Yang et al. (2005), Zhang et al. (2012), and Long et al. (2013) have agreed that oil sludge is usually composed of $30-70 \%$ water, 2 to $15 \%$ sediments and solids, and 30-90\% oil. Moreover, Egazar'yants et al. (2015) mentioned that oil sludges can have approximately 10 to 56 wt.\% organic materials, 30 to $85 \mathrm{wt} . \%$ water and 1 to $46 \mathrm{wt} . \%$ solids or sediments. This shows that there is no uniform agreement among authors on the detailed oil sludge composition. This is not surprising since each oil sludge composition is unique, and depends on the origin of the oil sludge (Viana et al., 2015). Consequently, the physicochemical characteristics vary according to the nature of the oil (Oliveira et al., 2015) and the formation process and storage of the oil sludge (Kadiev et al., 2015). Generally, the sediment content is less than the oil and water contents. The oil usually had higher aliphatic hydrocarbon percentages (40-60\%) than the aromatic hydrocarbon percentages (25-40\%) (Shie et al., 2004, Speight, 2006). This wide variation in the composition of oil sludges has significant implications on the characterisation of oil sludges because different procedures and methods have been applied to study different types of sludges (Heidarzadeh et al., 2010, Wang et al., 2010, Zhang et al., 2011, Jasmine and Mukherji, 2015). In turn, this is extremely relevant for quick decision-making purposes regarding the appropriate treatment of this waste. Currently, the treatment of oil sludges is aimed to either reduce the contaminants in the sludge or to recover the oil. The former includes some methods such as encapsulation (Johnson et al., 2015), bioremediation (Wang et al., 2016, Roy et al., 2018), and incineration (Gong et al., 2017) whereas the latter, the oil recovery methods, include freeze/thawing (Hu et al., 2015), solvent extraction (Hu et al., 2017, 
69 Nezhdbahadori et al., 2018), centrifugation (Wang et al., 2018), microwave irradiation

70 (Tsodikov et al., 2016), and surfactant enhanced oil recovery (Duan et al., 2018, Liu et al., 2018). The implications of using an oil recovery technique is that the recovered oil can be reused as feedstock for fuel production (Giles, 2010, Liu et al., 2011, Hu et al., 2015, Zhao et al., 2017). Indeed recently, most of the sludge treatment has been focused on recycling methods to recover the oil (Gumerov et al., 2017, Nezhdbahadori et al., 2018). For example, if the oil sludge has a high oil content, it could be extracted and re-used as fuel (Hu et al., 2013).

Oil sludges are accumulated during the extraction, refining, storage, and transportation of oil (Wang et al., 2010, Zhang et al., 2011). The common sources of oil sludges are the bottom of crude oil tanks, oil-water separators, desalinators, and oil wastewater treatment plants $(\mathrm{Hu}$ et al., 2013, Egazar'yants et al., 2015). In addition, oil sludge can be formed from waste engine oils from vehicles and machines (Lam et al., 2012).

Oil sludges accumulated at the bottom of the storage tanks are the most frequently analysed (Hu et al., 2013, Mansur et al., 2016), and only a limited number of studies have studied in detail oil sludges from different sources. For instance, Jin et al. (2014) assessed the water content in oil sludges from oil storage tanks, dissolved air flotation units, biological sludge produced during wastewater treatments, and petroleum product storage tanks in the oil refinery. Another study used oil refinery tank bottom sludges and oil tank cleaning water sludges to analyse the emulsified water in these samples (Huang et al., 2014). Therefore, it is increasingly important to perform more studies with oil sludges from different sources to determine differences to standardise procedures for their rapid characterisation and subsequent treatment.

Nuclear magnetic resonance (NMR) has been widely used in the determination of organic components of oil (e.g. aromatics, paraffins, olefins) in sludges (Mazlova and Meshcheryakov, 1999, Pánek et al., 2014, Kadiev et al., 2015, Cheng et al., 2016, Shen et al., 2016, Uçar et al., 
93 2016, Ma et al., 2018). NMR requires only a relatively small sample amount, and it is non94 sample destructive (Zheng et al., 2013). It has an acceptable ${ }^{1} \mathrm{H}$ sensitivity, and it is easy to measure (Silva et al., 2012). However, other methods used to determine the oil hydrocarbon content such as azeotropic distillation need a high amount of reactants (e.g. approximately 200

$97 \mathrm{ml}$ of toluene) (Jin et al., 2014). Recently, low-field NMR (below $100 \mathrm{MHz}$ ) has been used 98 effectively for a rapid assessment of oil and water contents in the sludges (Jin et al., 2013, 99 Zheng et al., 2013, Jin et al., 2014) and in crude oil-water emulsions (LaTorraca et al., 1998, 100 Silva et al., 2012). High-field NMR is a well-established and widely available analytical 101 method that has the potential to distinguish between aliphatic and aromatic components as well 102 as to access the water-to-oil ratio in one experiment. However, to our knowledge, there are no 103 high-field NMR studies which aim to elucidate aliphatic and aromatic contributions and compare water-to-oil ratios for contrasting characteristic sludges originating from different sources..

The aim of this study was to analyse different types of oil sludges, but with the high-field NMR (500 MHz), to prove that high-field NMR could also be a rapid method to analyse the oil and water content in various sludges. Also, the oil hydrocarbon fractions, trace elements, sediment content, and PTEs were analysed. Therefore, we proposed a scheme to characterise

110 the oil sludges in this study. Such information is crucial to make decisions regarding the most 111 suitable treatment for these wastes. For instance, if the composition of the oil hydrocarbons in 112 the sludge is known, the possibility to recover the oil for future fuel production could be 113 assessed in a high degree of certainty minimising the recovery costs.

\section{2. Materials and Methods}




\subsection{Oil sludges}

118

Five oil sludges were used: An oil drilling sludge (ODS), an oil refinery sludge (NSC), an oil-water separator sludge (WSS), and two waste engine oil sludges (STS and RS). Oil sludge samples were stored in amber glass containers at $4^{\circ} \mathrm{C}$ to avoid photodegradation and volatilisation.

\subsection{Total dry matter and water contents}

Dry matter and water contents were assessed according to the European Committee for Standardisation (CEN) protocol (EN12880, 2003). The total dry matter content comprised the dried solid and organic material contents. Briefly, the oil sludge ( $5 \mathrm{~g}$ ) was added to a crucible previously dried at $105^{\circ} \mathrm{C}$ for 30 minutes. The crucible was then dried at $105^{\circ} \mathrm{C}$ for 24 hours.

130 The weight was continually registered until a constant mass was reached. 30 minutes (Taiwo and Otolorin, 2009). The organic material content was the mass lost in the heating at this high temperature (Zubaidy and Abouelnasr, 2010).

\subsection{Metal elements analysis}


139 Kjeldahl digestion tube. In addition, four glass balls $(1.5 \mathrm{~mm}-2 \mathrm{~mm}), 10.5 \mathrm{ml}$ of concentrated

140 hydrochloric acid, and $3.5 \mathrm{ml}$ of concentrated nitric acid (both AnalaR grade supplied by

141 Sigma-Aldrich) were added. The tube was left overnight in a fume cupboard. After, it was

142 heated at $50^{\circ} \mathrm{C}$ in a digestion block.. The temperature was then increased at $5^{\circ} \mathrm{C} \cdot \mathrm{min}^{-1}$ to $140^{\circ} \mathrm{C}$.

143 The sample was left at this temperature for two and half hours and filtered into a 100-ml

144 volumetric flask using a Whatman Grade 540 filter paper (Sigma-Aldrich). The final volume

145 (100 ml) was reached with $0.5 \mathrm{M}$ nitric acid and then diluted 10-fold with ultrapure water (18.2

$146 \mathrm{M} \Omega \cdot \mathrm{cm})$. An inductively coupled plasma optical emission spectrometer (ICP-OES) (Optima

$1477300 \mathrm{DV}$ ) was used to analyse the sample and the multi-element and arsenic standards. The

148 data had no total metal values because this type of digestion did not dissolve any silicates,

149 therefore, analysed metals were only aqua regia soluble.

150

\subsection{High field NMR}

A Bruker Avance III $500 \mathrm{MHz}$ NMR spectrometer (Bruker Biospin, Germany) operating at a Larmor frequency of $500.13 \mathrm{MHz}(11.75 \mathrm{~T})$ was used in conjunction with a Bruker broadband observe (BBO) high-resolution solution probe. Standard $5 \mathrm{~mm}$ diameter NMR tubes (Norell S 5-400-7) were used. A sample volume of $200 \mu 1$ guaranteed that the entire sample was inside the active space of the radiofrequency coils from the BBO probe. Used motor oil (ca. $0.5 \mathrm{~mL}$ ) diluted in $0.5 \mu \mathrm{L}$ of deuterated benzene (Sigma-Aldrich) was the shim and lock standard. This was necessary to ensure a maximum possible homogeneity of the magnetic field and optimal and reproducible conditions for recording the NMR signal which

161 cannot be reached using the sludges due to the numerous impurities. After the shims were

162 calibrated with this standard, no shimming and locking was executed in the samples. 

decay data were reported (all samples) at room temperature. The $90^{\circ}$ pulse lasted $10 \mu$ s at 17 W. In total, eight signal transients were averaged in a free induction decay, FID (39,990 data points, dwell time $=3.33 \mu \mathrm{s})$. The spectral resolution was $3.75 \mathrm{~Hz}$ corresponding to a wide

167 spectral width of $150 \mathrm{kHz}$. A full relaxation of the spins was guaranteed with a relaxation delay between 20 and $15 \mathrm{~s}$. sequence. In total 128 echo cycles were used in one experiment. Each cycle consisted of an even number of echo loops with a fixed echo time of $0.26 \mathrm{~ms}$ (milliseconds). The number of echo loops increased non-monotonically in each consecutive cycle from 2 to 8192 to correctly cover the fast decay of oil and slow decay of water signals (e.g. frequent at short and sparse at long times). The FID signal (half of the spin echo) was registered after each cycle and was decomposed as a function of time using Fourier transformations. A 1D NMR spectrum slice was then obtained, and each slice was phase and baseline corrected prior to the integration of the full spectral range. The final $\mathrm{T}_{2}$ decay curve for each sample comprised the series of integrals as a function of the echo time for each cycle. These data were obtained with TopSpin v. 3.5 pl 5 (Bruker Biospin, Germany). components which corresponded to the oil and water present in the samples and a background 182 constant using Microsoft ${ }^{\circledR}$ Excel $^{\circledR}$ 2016. The $\mathrm{T}_{2}$ decay times for oil and water, as well as 183 corresponding signal amplitudes, were obtained from the fitting. The percentage of the amplitudes of the fit components were used to calculate the oil and water contents. This (ca. $1000 \mathrm{~ms}$ ) signals. 
$188 \mathrm{R}^{2}$ values found between the NMR data and the expected percentage values of the oil and water

189 standards. In addition, the percentage differences between the $\mathrm{T}_{2}$ decay and $1 \mathrm{D}$ proton data of 190 the oil-water calibration standards were gathered to confirm the consistency of the NMR

191 method in calculating the oil and water contents in the oil sludges. The aliphatic to aromatic

192 ratio in the oil sludges was calculated with the integrated intensities of the peaks in the ${ }^{1} \mathrm{H}$ NMR 193 spectrum at the specified regions (aliphatic or aromatic).

194

195

196

197

198

200

201

202

203

204

205

\subsection{Extraction of extractable petroleum hydrocarbons (EPH)}

\section{from the oil sludges}



$130^{\circ} \mathrm{C}$ for 16 hours before the SPE clean-up process. Silica gel was finally deactivated with $3 \%(\mathrm{w} / \mathrm{v})$ of deionised water. Sand (50-70 mesh particle size) (Sigma-Aldrich) was activated at $400^{\circ} \mathrm{C}$ during 8 hours. Silica gel $(1 \mathrm{~g})$, anhydrous sodium sulphate $(0.5 \mathrm{~g})$ and sand $(1 \mathrm{~g})$ were added as sorbents into a SPE cartridge (Supelco). The SPE cartridge was placed in a Visiprep $^{\mathrm{TM}}$ vacuum manifold (Supelco) at a pressure of $250 \mathrm{~mm} \mathrm{Hg}$. Sample $(0.5 \mathrm{ml})$ was then transferred to the SPE cartridge, and both the aliphatic and aromatic fractions were eluted with $3.5 \mathrm{ml}$ of hexane and $9 \mathrm{ml}$ of $3 \%$ of isopropanol diluted in hexane, respectively. The eluents were finally evaporated to $1 \mathrm{ml}\left(40^{\circ} \mathrm{C}\right)$ with a gentle nitrogen stream.

\subsubsection{Analysis of the EPH fractions by gas chromatography-} flame ionisation detection (GC-FID) and $95 \%$ siloxane,30 m, $0.32 \mathrm{~mm}$, and $0.25 \mu \mathrm{m}$ ) supplied by Sigma-Aldrich. The injection volume was $1 \mu \mathrm{l}$ in splitless mode. The make-up gas was nitrogen $\left(25 \mathrm{ml} \cdot \mathrm{min}^{-1}\right)$, and the carrier gas was helium $\left(3 \mathrm{ml} \cdot \mathrm{min}^{-1}\right)$. The hydrogen and air flowed at 30 and $400 \mathrm{ml} \cdot \mathrm{min}^{-1}$, respectively.

230 The inlet and detector temperatures were held at 285 and $320^{\circ} \mathrm{C}$, respectively. The oven temperature was held at $60^{\circ} \mathrm{C}$ for one minute, then ramped at $8{ }^{\circ} \mathrm{C} \cdot \mathrm{min}^{-1}$ to $290^{\circ} \mathrm{C}$, and held for 
2326.75 minutes. The total programme time was $36.5 \mathrm{~min}$. The calibration standards were EPH 233 aliphatic hydrocarbons and polynuclear aromatic hydrocarbons mixtures (Sigma-Aldrich). The 234 OpenLab CDS Chemstation Edition software Version C.01.07 (Agilent Technologies) was 235 used to extract and analyse the chromatograms. The EPH fractions analysed were the $\mathrm{C}_{10}-\mathrm{C}_{18}$ 236 and $\mathrm{C}_{19}-\mathrm{C}_{36}$ aliphatic fractions, and the $\mathrm{C}_{11}-\mathrm{C}_{22}$ aromatic fraction. The total $\mathrm{EPH}$ concentration 237 was the sum of the three fractions mentioned above.

\section{Results and Discussion}

\subsection{Oil sludges}

The oil sludges were obtained in the UK. The sludges presented a semi-solid condition at room temperature (Figure S 1). The WSS sludge was from an oil-water separator used in an oil refinery facility. The appearance of this sludge was black and viscous. The ODS sample was a sludge from an oil drilling process with a brown and viscous appearance. The STS and RS samples were obtained from two metal removal procedures (i.e. gravitational settling for STS and centrifugation for RS) applied to waste engine oils mixed with oil additives. RS seemed more viscous than STS. The NSC sample was viscous and black and was obtained from an oil refinery process. The datasets used in this study are publicly available on the Mendeley data repository linked to this work.

\subsection{Characteristics of oil sludges}



(including PTEs). Table 1 shows the total dry matter (organic material and solids) and water contents of the oil sludge samples.

Table 1. Percentages of water and total dry matter in the oil sludges.

\begin{tabular}{lccc}
\hline & & \multicolumn{2}{c}{ Total dry content } \\
Sludge & Water content & Solid content & Organic material \\
\cline { 3 - 4 } WSS & $47( \pm 1)$ & $23( \pm 0.93)$ & $30( \pm 2)$ \\
ODS & $13( \pm 0.02)$ & $86( \pm 0.11)$ & $1( \pm 0.10)$ \\
STS & $41( \pm 0.16)$ & $35( \pm 0.16)$ & $24( \pm 0.09)$ \\
RS & $35( \pm 2)$ & $38( \pm 0.17)$ & $27( \pm 2)$ \\
NSC & $60( \pm 2)$ & $1( \pm 0.07)$ & $39( \pm 2)$ \\
\hline * Each result is the mean $(n=3)$ with the standard deviation is in parentheses.
\end{tabular}

* Each result is the mean $(n=3)$ with the standard deviation is in parentheses

The solid and organic material comprised the total dry contents. Figure S 1 shows the oil sludges prior to the water and total dry content determination and after heating at $105^{\circ} \mathrm{C}$ and $550^{\circ} \mathrm{C}$ to determine the water and solid contents, respectively. The highest dry matter content of $87 \%( \pm 0.02)$ was found in the ODS sludge arising from the high solids in the mud accumulated in the oil drilling operations. The picture of the solid content in Figure $\mathrm{S} 1$ shows the drilling mud of the ODS sludge after heating at $550^{\circ} \mathrm{C}$. ODS had the lowest water content $(13 \% \pm 0.02)$ (Table 1). Even though the STS and RS samples had the same origin (the content of organic material was not significantly different, $\mathrm{p}=0.104, \alpha=0.05$ ), the paired $\mathrm{t}$-test confirmed that the water content was significantly lower for RS than STS $(p=0.015)$. In

271 addition, the solid content was significantly higher for RS than STS $(\mathrm{p}<0.01)$. 

content $(1 \% \pm 0.07)$ due to the highest dried organic material present in this sludge $(39 \% \pm 2)$. In fact, the picture of the solid content of this sludge shows the residual ash after burning at $550^{\circ} \mathrm{C}$ (Figure $\mathrm{S} 1$ ). The high organic material content in NSC could be partially related with heavy oil hydrocarbon fractions due to the heating at $550^{\circ} \mathrm{C}$. In fact, Zubaidy and Abouelnasr (2010) mentioned that the oil mass fraction is an estimated value of the organic material content in the sludge. Therefore, this information is important because it shows that the oil sludge has the potential to be treated by an oil recovery method. In addition, NSC had the highest water content $(60 \% \pm 2)$. However, it was expected that NSC had the lowest water content because this sample was an oil-refined sludge with mostly crude oil, which was evidenced after drying at $105^{\circ} \mathrm{C}$ (Figure $\mathrm{S} 1$ ). This low water content can be due not only to water loss but also to the volatilisation of light hydrocarbons after heating at $105^{\circ} \mathrm{C}$. Therefore, the method used in this study overestimated the water content value in the sludge. Jin et al. (2014) also found that the oven-drying method for the assessment of water content was overestimating its content value due to volatilisation of oil hydrocarbons. Even though this method was overestimating the contents of water in the present study, it is suitable to determine the sediment or dry content in oil sludges. If other methods such as thermogravimetric analysis (TGA) method were used to determine the dry content of the oil sludge coupled with Fourier-transform infrared spectroscopy (FTIR), this could distinguish water from light hydrocarbons. had higher concentrations in most of the metals than the other samples. The oil sludges were under the limit of acceptable concentrations in metals for landfilling purposes fixed by the European Union (Kriipsalu et al., 2008). The WSS sample had higher PTE levels than other samples with $\mathrm{Cr}(85 \pm 0.44), \mathrm{Cu}(142 \pm 3), \mathrm{Zn}(376 \pm 7)$ and $(\mathrm{Ni} 85 \pm 0.58) \mathrm{ppm}$. The 
297 concentrations were also higher than the limit in the other sludges. The higher levels of $\mathrm{Zn}$ in 298 all sludges were expected since this metal can be found in the porphyrin compounds from 299 petroleum (Jasmine and Mukherji, 2015). Ca and Fe were the elements with the highest 300 concentrations in all sludges $\left(>1,000 \mu \mathrm{g} \cdot \mathrm{g}^{-1}\right)$. For example, Fe concentrations were higher in 301 STS $(16,146 \pm 252 \mathrm{ppm})$ and RS sludge $(13,915 \pm 278)$ than the other samples. This result 302 agreed with previous analysis of a tank bottom oil sludge (Jasmine and Mukherji, 2015) who proposed that the high concentrations of $\mathrm{Ca}$ and $\mathrm{Fe}$ can be due to calcite minerals and the material of the tank walls, respectively. Moreover, Schirmacher et al. (1993) reported that usually high concentrations of $\mathrm{Zn}, \mathrm{Ca}$, and $\mathrm{Fe}$ are obtained from oil sludges. Also, da Rocha et al. (2010) found high Fe levels $(34,500 \mathrm{ppm})$ in an oil refinery tank bottom sludge, and

307 Karamalidis et al. (2008) reported a Fe concentration of 92,179 ppm in an oil refinery sludge.

308 Other trace elements analysed included $\mathrm{Ba}, \mathrm{K}, \mathrm{Li}, \mathrm{Mg}, \mathrm{Mn}, \mathrm{Na}$, and $\mathrm{Sr}$, and these levels were higher for WSS than the other samples. There were no results for NSC due to the limitation on the amount of the sample. These results showed the importance to consider the analysis of the trace elements in the oil sludges, so this should be also considered in the decision-making of the treatment of these wastes. Hu et al. (2013) mentioned the importance of the characterisation of heavy metals in oil sludges. For instance, if the oil is recovered to be reused as fuel, the metals can interfere with the catalysts used in thermal cracking of heavy to light oil hydrocarbon fractions (Elektorowicz and Muslat, 2008, Khan et al., 2019). Also, it has been reported that $\mathrm{Ni}$ and $\mathrm{V}$ in interaction with $\mathrm{Na}$ in the recovered oil from the oil sludge can originate corrosion issues in the petroleum facilities (Abbas et al., 2010). The WSS sludge had the highest concentrations of most of the PTEs, so its treatment can include a strategy to contain these elements. For instance, if pyrolysis is applied to treat this sludge, the PTEs can be concentrated in the char, the final solid product of the process (Shen and Zhang, 2003). 


\subsection{High-field NMR (oil and water contents)}

Firstly, different oil and water mixtures standards were evaluated to validate the NMR procedure. Figure S 2 shows the ${ }^{1} \mathrm{H}$ spectra of these standards. All spectra showed two broad resonances attributed to oil (centred at ca. 2.4ppm) and water (centred at ca. $5.4 \mathrm{ppm}$ ) which are consequent with the expected oil and water contents in the standards. For instance, the ${ }^{1} \mathrm{H}$ spectrum of the oil $80 \%$ + water $20 \%$ standard at the top of Figure S 2 shows the high content of oil in the high intensity peak at c.a. 2.4 ppm whereas the oil $20 \%+$ water $80 \%$ (i.e. the spectrum at the bottom of Figure S 2) shows a high intensity peak at c.a. 5.4 ppm attributed to water. A fair resolution of the spectra allowed direct integration of the signals attributed to oil and water. The peaks found in the ${ }^{1} \mathrm{H}$ spectra corresponded to the aliphatic carbon fraction from 0.5 to $4 \mathrm{ppm}$ and the aromatic carbon fraction from the 6 to $9 \mathrm{ppm}$ region. In the case of the

${ }^{13} \mathrm{C}$ spectra (Figure $\mathrm{S} 3$ ), the $10-60 \mathrm{ppm}$ and $110-160 \mathrm{ppm}$ regions corresponded to the aliphatic and aromatic carbon fractions, respectively (Ancheyta et al., 2002, Trejo et al., 2005, Nakada et al., 2016). Figure $\mathrm{S} 3$ shows that the oil from the standards had a presence of the aliphatic fraction because there are some peaks after c.a. $15 \mathrm{ppm}$ to $40 \mathrm{ppm}$, and there were no signals characteristic of aromatic carbons. The intensities of the peaks between 15 and 40 ppm were consistent with the proportion of oil in the standard. Therefore, the standard with the highest oil content (i.e. oil $80 \%$ + water $20 \%$ standard; top of Figure S 3) showed peaks with high intensity. Conversely, the standards with low oil content showed peaks with low intensity.

342 These results showed the potential use of high field NMR to differentiate between aliphatic and aromatic components in the ${ }^{13} \mathrm{C}$ spectra. 
346 (integral) as a function of the echo time. These data were compared with the expected

347 percentage values in Table 2.

Table 2. Oil and water mixture standards with the relative errors of the expected and experimental values and percentage differences of the $T_{2}$ decay and 1D proton spectra data.

\begin{tabular}{|c|c|c|c|c|c|}
\hline Std $^{1}$ & $\begin{array}{l}\text { Nominal } \\
\text { values } \\
\text { (fraction) }\end{array}$ & $\begin{array}{l}\text { Experimental } \\
\text { value }\left(\mathbf{T}_{2}\right. \\
\text { decay) }\end{array}$ & $\begin{array}{c}\text { Relative } \\
\text { error }^{2}\left(\mathrm{~T}_{2}\right. \\
\text { decay })(\%)\end{array}$ & $\begin{array}{l}\text { 1D proton } \\
\text { spectra } \\
\text { (integrals) }\end{array}$ & $\begin{array}{c}\text { Difference between T2 } \\
\text { decay and 1D proton } \\
\text { values }(\%)\end{array}$ \\
\hline \multirow[t]{2}{*}{1} & Oil (0.2) & 0.17 & 16 & 0.14 & 19 \\
\hline & Water $(0.8)$ & 0.83 & 4 & 0.86 & 3 \\
\hline \multirow[t]{2}{*}{2} & Oil (0.4) & 0.34 & 14 & 0.33 & 3 \\
\hline & Water (0.6) & 0.66 & 9 & 0.67 & 1 \\
\hline \multirow[t]{2}{*}{3} & Oil (0.5) & 0.47 & 5 & 0.53 & 12 \\
\hline & Water $(0.5)$ & 0.53 & 5 & 0.47 & 12 \\
\hline \multirow[t]{2}{*}{4} & Oil (0.7) & 0.62 & 11 & 0.61 & 2 \\
\hline & Water (0.3) & 0.38 & 26 & 0.39 & 2 \\
\hline \multirow[t]{2}{*}{5} & Oil (0.8) & 0.77 & 4 & 0.77 & 0 \\
\hline & Water (0.2) & 0.23 & 14 & 0.23 & 0 \\
\hline
\end{tabular}


oil and water contents (Table 2). Two experimental errors were higher than this threshold, the oil content in standard $1(16 \%)$ and the water content in standard $4(26 \%)$.

The percentage differences between the $\mathrm{CPMG} \mathrm{T}_{2}$ decay data and $1 \mathrm{D}$ proton spectra were lower than 5\% (except for standard 3 and the oil fraction in standard 1), which indicated a good agreement between both and supported the consistency of the results (Table 2).

The differences obtained between the expected and experimental values of the standards can be due to the difficulties in preparing the exact oil and water ratios. The NMR tubes were very narrow $(5 \mathrm{~mm})$, and it was necessary to load the sample with a long-tip Pasteur pipette to reach the bottom of the tube. It is possible that some small volume of the viscous liquid of the sample has remained in the pipette after the loading, so the exact nominal ratio was not obtained.

The linear regression of the NMR-calculated oil and water content as a function of the nominal values showed an acceptable linear correlation in both oil and water contents, and the $\mathrm{R}^{2}$ coefficient was 0.990 which confirms that the discrepancy between nominal and experimental values were due to problems with loading the standard samples into the NMR tube. This simple analysis allowed to estimate the maximum error related to preparation and manipulation of the samples to be no larger than $20 \%$. This value was considered for the calculation of the oil/water content experimental error in the sludges in the next step. a bimodal decay of the NMR signal intensity as a function of time, and these were attributed to oil and water in which the oil component relaxes faster than the water component (LaTorraca et al., 1998). Therefore, the standards with a high oil content (i.e. oil $80 \%$-water $20 \%$, oil $70 \%$ water $30 \%$, oil 50\%-water 50\%) showed seemingly a faster decay than the standards composed by a high-water content. This trend showed that the contribution of water and oil in the decay 
381 curve can be obtained by extracting the amplitudes of both components. The fraction content

382 of oil and water in each standard sample can be then calculated and results were presented as 383 showed in Table 2.

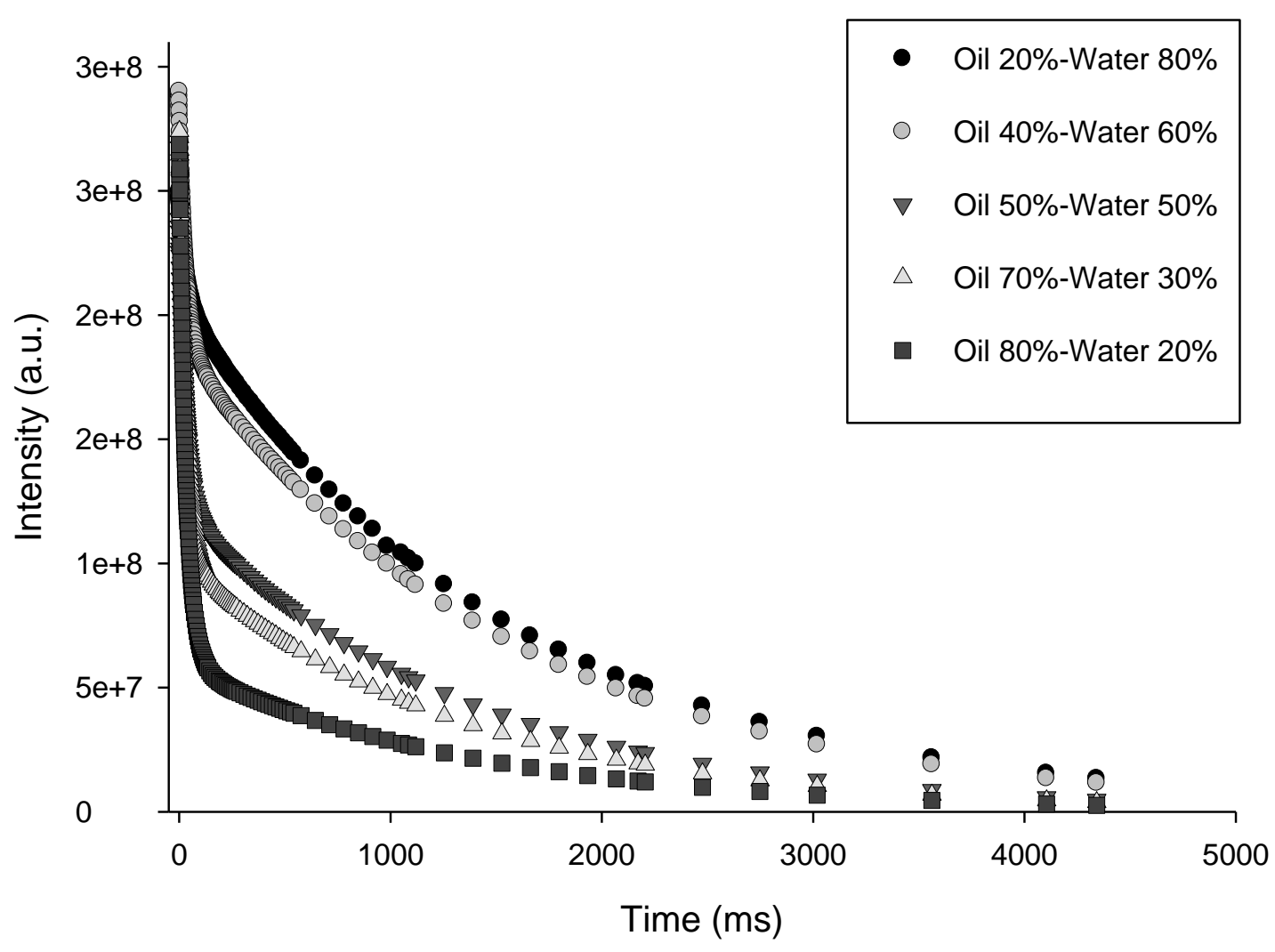

Figure 1. Carr-Purcell-Meiboom-Gill (CPMG) $\mathbf{T}_{2}$ relaxation decay curves of the oil and water mixtures standards (\%). T2 decay shows the decay of the signal intensity (integral) as a function of the echo time. 

very broad and poorly resolved resonances were detected as a result of the presence of numerous impurities. This critical broadening of the signals, often without distinguishable structure (Figure S 4) was directly related to the presence of the metallic and paramagnetic impurities in the oil sludges as shown in the trace metal elements concentrations data (Table $S$ 1). For instance, the ODS and RS spectra show broader signals than NSC that has more defined peaks (Figure S 4). These broad signals could probably due to the presence of more paramagnetic impurities compared to NSC. These impurities affected also the anticipated location in the 1D spectra of the oil and water peaks in the ODS and RS spectra and further prevented using them for the direct estimation of oil-to-water ratios by simple integration because appropriate regions of the spectrum were not resolved enough. Indeed, the lower the impurities content in the oil sludges, the higher the resolution of the different parts of the spectra in the high-field NMR.

Even though the paramagnetic impurities had generated broad signals in the spectra of the oil sludges, the aliphatic and aromatic ratio could be estimated in the NSC sample presumably due to a lower amount of paramagnetic impurities compared with the other sludges. Therefore, Figure S 4 shows the $1 \mathrm{H}$ spectrum of the NSC sludge where the aliphatic fraction was found approximately from 0 to $4.9 \mathrm{ppm}$ and the aromatic fraction from 6.8 to $12 \mathrm{ppm}$

410 (aliphatic to aromatic ratio $=0.82 / 0.03)$. The water fraction was found from 5-6.8 $\mathrm{ppm}(0.15)$.

412 due to significant broadening of the resonances) by this high content of metallic or 413 paramagnetic impurities (data not shown). These level of metals/paramagnetic impurities can

414 be qualitatively evaluated from the broadening of the NMR signals, but more studies with a 415 controlled level of those impurities are required. 
417 decay curves presented in Figure 2, and the obtained results with the oil and water contents in 418 the oil sludges are shown in Table 3.

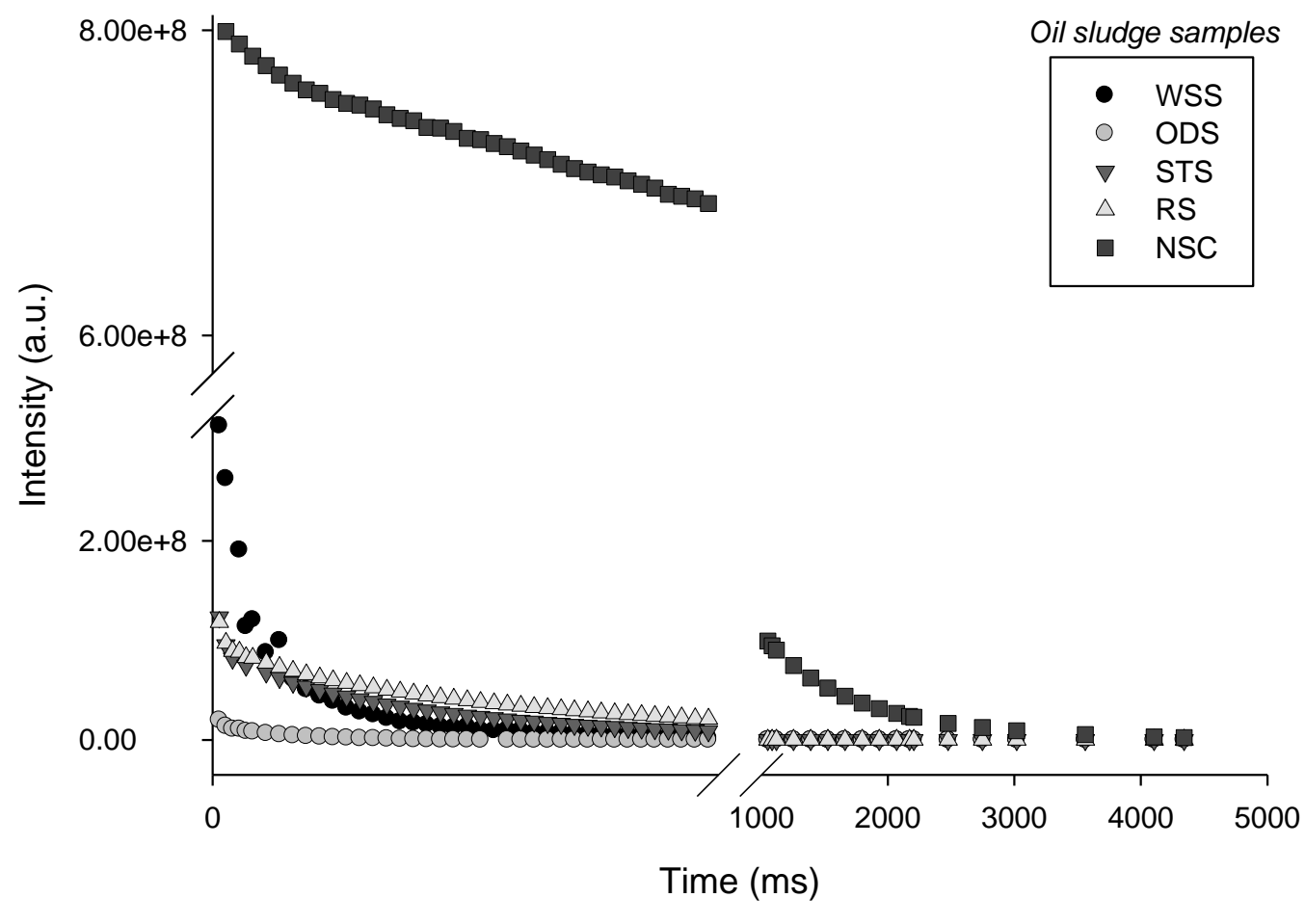

420

Figure 2. $T_{2}$ relaxation decay curves of the oil sludge samples (WSS, ODS, STS, RS, NSC). T 2 decay shows the decay of the signal intensity (integral) as a function of the echo time. resonance (NMR) of the oil sludges.

\begin{tabular}{lll}
\hline Sample & Oil (\%) & Water (\%) \\
\hline
\end{tabular}




\begin{tabular}{ccc}
\hline WSS & $81( \pm 6)$ & $19( \pm 6)$ \\
ODS & $1( \pm 0.26)$ & $99( \pm 0.26)$ \\
STS & $50( \pm 14)$ & $50( \pm 14)$ \\
RS & $39( \pm 1)$ & $61( \pm 1)$ \\
NSC & $88( \pm 11)$ & $12( \pm 11)$ \\
\hline
\end{tabular}

428

The CPMG $\mathrm{T}_{2}$ decay data (Figure 2) showed significant differences in the decay

430 behaviour among the sludges. However, as expected all decays showed "fast" and "slow" decay

431 components which could be attributed to oil and water (LaTorraca et al., 1998, Jin et al., 2013).

432 For example, the decay times for the RS sludge were $2 \mathrm{~ms}$ for oil and $30 \mathrm{~ms}$ for water. The

433 decay times of the oil and water standards results of $50 \mathrm{~ms}$ for the fast decay of oil and 1,500

$434 \mathrm{~ms}$ for the slow decay of water. As mentioned before, the clear difference in the decay of oil

435 and water between the oil sludge samples and standards is due to the presence of paramagnetic

436 and metallic impurities which have tendency to accumulate in the oil sludges and as a result,

437 shorten its relaxation.

438 When comparing the oil-to-water proportions obtained by the oven drying method with

439 those from high field NMR, it was found similar trends in the data (Table 3). However, the

440 water content in NSC obtained by high field NMR was the lowest value of all the sludges which

441 was the opposite to the result found in the oven-drying method (See Section 3.2. Characteristics

442 of oil sludges). This finding established that the water content was overestimated by the oven-

443 drying method with a five-fold increase. The oil content obtained by high field NMR was the

444 highest $(88 \% \pm 11)$ in the NSC sample, and this was confirmed by the highest value of organic

445 material content found in the oven-drying method. Also, the lowest organic material content in

446 ODS was confirmed with the low oil content found in the high field NMR method. WSS had a 
447 higher oil content compared to RS, STS, and ODS. Ramaswamy et al. (2007) mentioned that 448 oil sludges with oil contents above $10 \%$ are suitable for an oil recovery treatment from a 449 economic view. Therefore, all oil sludges samples except ODS (1\% of oil content; Table 3) 450 can be treated with an oil recovery technique such as oil sludge washing with surfactants 451 (Zheng et al., 2012, Ramirez and Collins, 2018). Then, the recovered oil can be potentially be reused as a feedstock for fuel production. Regarding the ODS sludge, an oil sludge contaminant reduction technique can be applied such as bioremediation due to the low oil content and PTEs concentrations in this sludge (Table S 1). It is necessary to emphasise that some caution has to be considered when analysing NMR intensity data for the oil sludges. This is related to the difficulties found with fitting the exponential function with the two components (oil and water) to the oil sludge intensity data. The underlying common problem is an uncertainty in fitting more than one exponential component to the experimental data. Such a problem is usually related to the difficulty to reach a precise $90^{\circ}$ pulsation which is especially important for the

460 long train of pulses in the CPMG pulse sequence. The small deviation in the pulse length may 461 adversely affect the echo intensity. The paramagnetic and salt contents contained in the oil 462 sludges could influence the variation of the precision in the $90^{\circ}$ pulses (Simpson et al., 2011). 463 The objective of the pulse sequences is to excite the signals of the sample, so the NMR 464 spectrometer can detect them (Derome, 1987). Despite this inconvenience, the validation of the method with the standards confirmed that the data was consistent within experimental errors to 466 establish the oil and water contents in the oil sludges. Also, the starting parameters for each 467 component were fixed and allowed to vary in the same range during the fit for all samples to 468 avoid unambiguity in the fitting of the exponential function to experimental data. 
474 that each sludge was unique.
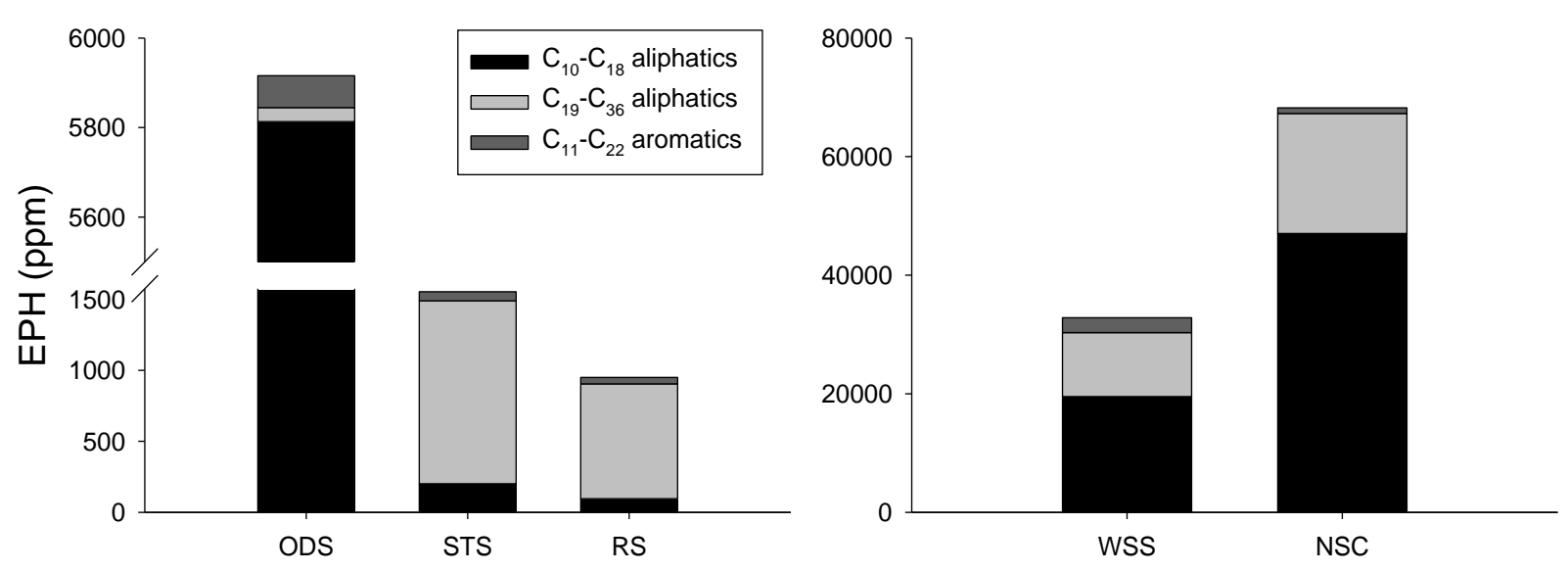

476

Figure 3. Mean values of the concentrations in ppm of the extractable petroleum hydrocarbons (EPH) fractions in the oil sludges.

479

\section{(THIS IS A 2-COLUMN FITTING IMAGE)}

480

$482( \pm 3,000)$, and 68,000 ( $\pm 6,070)$ ppm for ODS, STS, RS, WSS and NSC, respectively. The $\mathrm{C}_{19^{-}}$

$483 \mathrm{C}_{36}$ aliphatic fraction percentage was greater in the RS and STS with values of 83 and $85 \%$,

484 respectively, compared to the other samples (NSC, 30\%; WSS, 33\%; and ODS, 0.53\%). ODS,

485 NSC, WSS had high proportions of $\mathrm{C}_{10}-\mathrm{C}_{18}$ aliphatic fractions with 98, 70, and 60\%, 
respectively, whereas STS had $13 \%$ and $\mathrm{RS}$ had $10 \%$. All sludges showed low $\mathrm{C}_{11}-\mathrm{C}_{22}$ aromatic fraction concentrations, $1 \%-8 \%$ (Figure 3). In fact, the aliphatic fraction concentrations in oil sludges are usually higher than the aromatic fractions (Ward et al., 2003, Jasmine and Mukherji, 2015, Kadiev et al., 2015, Shahidi Rizi et al., 2017). RS chromatograms had unresolved complex mixtures (UCM) after $\mathrm{C}_{20}$. The UCMs are considered to be a group of overlapped compounds which cannot be determined by GC-FID (Frysinger et al., 2003), and these are usually found in crude oils at different stages of degradation (Peters et al., 2005). For instance, some biodegradation processes could occur in the storage tanks (where oil sludges can be found) due to the action of the native and crude oilresistant microbiota (Giles, 2010), and the water and sediments from the sludge could promote this biodegradation.

The UCMs were related with the high $\mathrm{C}_{19}-\mathrm{C}_{36}$ aliphatic fraction concentrations found in STS and RS (Figure 3, Figure S 5C and D). This presence of UCMs in RS and STS could be related with the fact that these sludges had waste engine oil with oil additives which is related with the lubrication feature of the oil. In fact, Gough and Rowland (1990) mentioned that UCMs are characteristic of lubricating oils and other refined oil fractions.

The information retrieved from EPH analyses can be an initial step to anticipate the probable reuse of the oil contained in the sludge. Therefore, the recovered oil can be reused as diesel fuel if a high light aliphatic fraction concentration is present (Zhao et al., 2017). For example, NSC and WSS with their high content of $\mathrm{C}_{10}-\mathrm{C}_{18}$ aliphatic hydrocarbon compounds can be treated with an oil recovery method to extract the oil and be reused. In fact, the GC

508 profile of NSC (Figure S 5E) was similar to the GC profile of the common crude oil, which indicates that this oil is an ideal candidate for reusing purposes due to its potential quality 
510 similar to pure crude oil. For instance, Villalanti et al. (2006) mentioned that GC can be used

511 as a rapid method for the analysis of the oil hydrocarbons fractions and gives information on

512 the potential reuse of crude oils. In addition, Hu et al. (2015) stated that the quality of the oil

513 can be evaluated by checking the EPH concentrations in the GC profiles. On the contrary, Giles

514 (2010) mentioned that the quality of the oil cannot be measured directly with GC profiles, and

515 that the oil must be fractionated by distillation methods to confirm its quality. Therefore, the

516 use in this study of the GC profiles was not contemplated as a complete validation of the oil

517 quality, but it was considered as an initial point to establish the potential reuse of the oil in the

518 fuel production. Other tests can be used to evaluate directly the quality such as the API gravity,

519 sulphur content, heat of combustion, and the pour and flash point (Zubaidy and Abouelnasr,

520 2010, Hu et al., 2015).

Regarding the ODS, STS, RS oil sludges, the total EPH concentrations were lower than

the suggested clean-up level of 10,000 ppm in soils in industrial areas (Shelley et al., 1997), so bioremediation techniques such as landfarming and phytoremediation of these oil sludges can be used to treat these sludges by its amending to a designated soil area (Ramirez and Dussan, 2014). In addition, the PTEs concentrations of these sludges (except for $\mathrm{Zn}$ ) were lower than the 2,500-ppm threshold (Table S 1). Higher concentrations than this threshold have been reported to be toxic for most microbiota (USEPA, 2004).

Since NSC and WSS had total EPH concentrations higher than 10,000 ppm, this bioremediation technique cannot be appropriate because these high concentrations can be toxic

530 for the microbiota and plants. In fact, it has been reported that EPH concentrations higher than $53150,000 \mathrm{ppm}$ are generally toxic for most of the microbiota (USEPA, 2004). Therefore, NSC $(68,000 \pm 6,070 \mathrm{ppm})$ must be pre-treated first with an oil recovery technique, and then a bioremediation technique can be selected to treat the residual sludge. 


\section{4. Conclusions}

536

The oil sludges used in this study came from different sources and presented a broad range of organic and inorganic co-contamination consistent with the high complexity present in this type of samples. It is very important to characterise in detail such complex samples because their treatment strongly depends on their composition. What is more, if the characterisation prior to treatment can be standardised for sludges from different sources, that would have a positive economic impact and more of such waste could be treated and recycled.

This study reported a use of different techniques to analyse different types of oil sludge samples, but uniquely in a uniform and standardised way, which gave complementary information about the water-to-oil ratio, aliphatic and aromatic components, sediment content, and trace elements and PTEs. Our comprehensive results showed that an oil recovery method (e.g. oil sludge washing with surfactants) can be applied in oil sludges with a high content of

548 oil such as the NSC and WSS sludges. Also, STS and RS are suitable to be treated with an oil recovery technique because the oil contents were higher than the $10 \%$ threshold which is economically acceptable.

The high PTEs concentrations in the WSS sample suggest that pyrolysis should be considered to contain these elements in the char, which is a solid product of this treatment. Our results also showed that the ODS sludge is only suitable to be treated by an oil sludge

554 contaminant reduction technique (e.g. bioremediation) due to its low oil content (1\%) and PTEs concentrations. Low PTE concentrations are not toxic for most of the microbiota used in bioremediation processes. 
This study showed that high-field NMR can be an alternative tool for waste researchers and petroleum engineers to rapidly calculate the water and oil contents, qualitatively access the concentration of the paramagnetic and metallic impurities, and in case of their absence or low concentration find the aliphatic and aromatic content of the sludges. The unquestionable advantage of this widely available analytical tool is that all that information could be potentially elucidated from a single ${ }^{1} \mathrm{H}$ NMR spectrum. However, more calibration studies are required to extend these procedures beyond the qualitative assessment.

The oven-drying method can determine the sediment content in the sludges. The assessment of oil hydrocarbons fractions by both GC-FID and high-field NMR can evaluate the possible reuse of the oil as fuel. Moreover, the gas chromatogram profiles provide evidence of a weathering condition and a possible degradation of the oil from the sludge by the presence of UCMs, as shown in the STS and RS samples. Due to the high concentration of some of the PTEs and their potentially hazardous effects, future studies should consider the analysis of these elements.

\section{Acknowledgements}

Diego Ramirez would like to thank the Colombian Administrative Department of Science,

576 Technology and Innovation, Colciencias, for the financial support from the Call 529 (2011) during his $\mathrm{PhD}$ studies. The funding source did not have any involvement in design, development and production of this study. 


\section{References}

Abbas, S., Maqsood, Z. T. and Ali, M. F. (2010) 'The Demetallization of Residual Fuel Oil and Petroleum Residue', Petroleum Science and Technology, 28(17), pp. 1770-1777.

Ancheyta, J., Centeno, G., Trejo, F., Marroquín, G., García, J. A., Tenorio, E. and Torres, A. (2002) 'Extraction and Characterization of Asphaltenes from Different Crude Oils and Solvents', Energy \& Fuels, 16(5), pp. 1121-1127.

Chen, J. Y., Luong, H. V. T. and Liu, J. C. (2015) 'Fractionation and release behaviors of metals (In, Mo, Sr) from industrial sludge', Water Research, 82, pp. 86-93.

Cheng, S., Wang, Y., Gao, N., Takahashi, F., Li, A. and Yoshikawa, K. (2016) 'Pyrolysis of oil sludge with oil sludge ash additive employing a stirred tank reactor', Journal of Analytical and Applied Pyrolysis, 120(Supplement C), pp. 511-520.

da Rocha, O. R. S., Dantas, R. F., Duarte, M. M. M. B., Duarte, M. M. L. and da Silva, V. L. (2010) 'Oil sludge treatment by photocatalysis applying black and white light', Chemical Engineering Journal, 157(1), pp. 80-85.

da Silva, L. J., Alves, F. C. and de França, F. P. (2012) 'A review of the technological solutions 596 for the treatment of oily sludges from petroleum refineries', Waste Management \& Research, 30(10), pp. 1016-1030.

de Souza, E. S., Fernandes, A. R., de Souza Braz, A. M., Sabino, L. L. L. and Alleoni, L. R. F. (2014) 'Potentially toxic elements (PTEs) in soils from the surroundings of the TransAmazonian Highway, Brazil', Environmental Monitoring and Assessment, 187(1), pp.

601 1-20.

602

Derome, A. E. (1987) Modern NMR Techniques for Chemistry Research. Great Britain: Pergamon Press Ltd. 
604 Duan, M., Wang, X., Fang, S., Zhao, B., Li, C. and Xiong, Y. (2018) 'Treatment of Daqing oily 605 sludge by thermochemical cleaning method', Colloids and Surfaces A:

606 Physicochemical and Engineering Aspects, 554, pp. 272-278.

607

Egazar'yants, S. V., Vinokurov, V. A., Vutolkina, A. V., Talanova, M. Y., Frolov, V. I. and 608 Karakhanov, E. A. (2015) 'Oil Sludge Treatment Processes', Chemistry and Technology of Fuels and Oils, 51(5), pp. 506-515.

Elektorowicz, M. and Muslat, Z. (2008) 'Removal of heavy metals from oil sludge using ion exchange textiles', Environmental Technology, 29(4), pp. 393-399.

EN12880 2003. Chemical Analyses-Determination of dry matter and water content on a mass basis in sediment, sludge, soil, and waste-Gravimetric method. European Committee of Standardization (CEN).

Frysinger, G. S., Gaines, R. B., Xu, L. and Reddy, C. M. (2003) 'Resolving the Unresolved Complex Mixture in Petroleum-Contaminated Sediments', Environmental Science \& Technology, 37(8), pp. 1653-1662.

Giles, H. (2010) 'Crude Oils', in Rand, S. (ed.) Significance of Tests for Petroleum Products. Eight ed. West Conshohocken, PA, USA: ASTM International.

Gong, Z., Du, A., Wang, Z., Fang, P. and Li, X. (2017) 'Experimental Study on Pyrolysis 621 Characteristics of Oil Sludge with a Tube Furnace Reactor', Energy \& Fuels, 31(8), pp.

Gough, M. A. and Rowland, S. J. (1990) 'Characterization of unresolved complex mixtures of hydrocarbons in petroleum', Nature, 344(6267), pp. 648-650.

Gumerov, F. M., Khairutdinov, V. F., Akhmetzyanov, T. R., Gabitov, F. R., Zaripov, Z. I., 626 Farakhov, M. I. and Mukhutdinov, A. V. (2017) 'Supercritical Fluid Propane-Butane Extraction Treatment of Oil Sludge', Russian Journal of Physical Chemistry B, 11(7), pp. 1103-1108. 
629 Heidarzadeh, N., Gitipour, S. and Abdoli, M. A. (2010) 'Characterization of oily sludge from a Tehran oil refinery', Waste Management \& Research, 28(10), pp. 921-927.

Hu, G., Li, J. and Hou, H. (2015) 'A combination of solvent extraction and freeze thaw for oil recovery from petroleum refinery wastewater treatment pond sludge', Journal of Hazardous Materials, 283, pp. 832-840.

Hu, G., Li, J. and Zeng, G. (2013) 'Recent Development in the Treatment of Oily Sludge from Petroleum Industry - A Review', Journal of Hazardous Materials, 261, pp. 470-490.

Hu, J., Gan, J., Li, J., Luo, Y., Wang, G., Wu, L. and Gong, Y. (2017) 'Extraction of crude oil from petrochemical sludge: Characterization of products using thermogravimetric analysis', Fuel, 188, pp. 166-172.

Huang, Q., Mao, F., Han, X., Yan, J. and Chi, Y. (2014) 'Characterization of emulsified water 640 in petroleum sludge', Fuel, 118, pp. 214-219.

Jasmine, J. and Mukherji, S. (2015) 'Characterization of oily sludge from a refinery and biodegradability assessment using various hydrocarbon degrading strains and reconstituted consortia', Journal of Environmental Management, 149, pp. 118-125.

Jin, Y., Zheng, X., Chi, Y. and Ni, M. (2013) 'Rapid, Accurate Measurement of the Oil and Water Contents of Oil Sludge Using Low-Field NMR', Industrial \& Engineering Chemistry Research, 52(6), pp. 2228-2233.

Jin, Y., Zheng, X., Chi, Y. and Ni, M. (2014) 'Experimental Study and Assessment of Different 649 Measurement Methods of Water in Oil Sludge', Drying Technology, 32(3), pp. 251257.

Johnson, O. A., Madzlan, N. and Kamaruddin, I. (2015) 'Encapsulation of petroleum sludge in 651 building blocks', Construction and Building Materials, 78, pp. 281-288. 
652 Kadiev, K. M., Gyulmaliev, A. M., Batov, A. E., Kadieva, M. K., Oknina, N. V. and Dandaev,

653

654

655

656

657

658

659

660

661

662

663

664

665

666

667

668

669

670

671

672

673

674

675

A. U. (2015) 'Structural characteristics of petroleum sludge', Coke and Chemistry, 58(11), pp. 448-450.

Karamalidis, A. K., Psycharis, V., Nicolis, I., Pavlidou, E., Bénazeth, S. and Voudrias, E. A. (2008) 'Characterization of stabilized/solidified refinery oily sludge and incinerated refinery sludge with cement using XRD, SEM and EXAFS', Journal of Environmental Science and Health, Part A, 43(10), pp. 1144-1156.

Khan, M. K., Cahyadi, H. S., Kim, S.-M. and Kim, J. (2019) 'Efficient oil recovery from highly stable toxic oily sludge using supercritical water', Fuel, 235, pp. 460-472.

Kriipsalu, M., Marques, M. and Maastik, A. (2008) 'Characterization of oily sludge from a wastewater treatment plant flocculation-flotation unit in a petroleum refinery and its treatment implications', Journal of Material Cycles and Waste Management, 10(1), pp. 79-86.

Lam, S. S., Russell, A. D., Lee, C. L. and Chase, H. A. (2012) 'Microwave-heated pyrolysis of waste automotive engine oil: Influence of operation parameters on the yield, composition, and fuel properties of pyrolysis oil', Fuel, 92(1), pp. 327-339.

LaTorraca, G. A., Dunn, K. J., Webber, P. R. and Carlson, R. M. (1998) 'Low-field NMR determinations of the properties of heavy oils and water-in-oil emulsions', Magnetic Resonance Imaging, 16(5-6), pp. 659-662.

Liu, C., Zhang, Y., Sun, S., Huang, L., Yu, L., Liu, X., Lai, R., Luo, Y., Zhang, Z. and Zhang, Z. (2018) 'Oil recovery from tank bottom sludge using rhamnolipids', Journal of Petroleum Science and Engineering, 170, pp. 14-20.

Liu, J., Jiang, X. and Han, X. (2011) 'Devolatilization of oil sludge in a lab-scale bubbling fluidized bed', Journal of Hazardous Materials, 185(2-3), pp. 1205-1213. 
676 Long, X., Zhang, G., Shen, C., Sun, G., Wang, R., Yin, L. and Meng, Q. (2013) 'Application of rhamnolipid as a novel biodemulsifier for destabilizing waste crude oil', Bioresource Technology, 131, pp. 1-5.

Ma, Z., Xie, J., Gao, N. and Quan, C. (2018) 'Pyrolysis behaviors of oilfield sludge based on Py-GC/MS and DAEM kinetics analysis', Journal of the Energy Institute.

Mansur, A. A., Taha, M., Shahsavari, E., Haleyur, N., Adetutu, E. M. and Ball, A. S. (2016) 682 'An effective soil slurry bioremediation protocol for the treatment of Libyan soil contaminated with crude oil tank bottom sludge', International Biodeterioration \& Biodegradation, 115, pp. 179-185.

Mazlova, E. A. and Meshcheryakov, S. V. (1999) 'Ecological characteristics of oil sludges', Chemistry and Technology of Fuels and Oils, 35(1), pp. 49-53.

Mirghaffari, N. 'Treatment and recycling of oily sludges produced in the petroleum industry'. 2017 International Conference on Environmental Impacts of the Oil and Gas Industries: Kurdistan Region of Iraq as a Case Study (EIOGI), 17-19 April 2017, 1-2.

Nakada, R., Waseda, A., Okumura, F. and Takahashi, Y. (2016) 'Impact of the decarboxylation reaction on rare earth elements binding to organic matter: From humic substances to crude oil', Chemical Geology, 420, pp. 231-239.

Nezhdbahadori, F., Abdoli, M. A., Baghdadi, M. and Ghazban, F. (2018) 'A comparative study 694 on the efficiency of polar and non-polar solvents in oil sludge recovery using solvent with ARGUS GmbH. extraction', Environmental Monitoring and Assessment, 190(7), pp. 389.

Okopol 2008. Review of the European List of Waste. Germany: Ökopol GmbH in cooperation 'Fractionation of oily sludges produced in the treatment of hydrocarbon wastes', in Vilarinho, C., Castro, F. \& Russo, M. (eds.) Wastes: Solutions, Treatments and 

September 2015. London, UK: CRC Press, pp. 189.

Peters, K. E., Walters, C. C. and Moldowan, J. M. (2005) The Biomarker Guide. Volume 1: Biomarkers and Isotopes in the Environment and Human History. Second edn. (2 vols). Cambridge, Untied Kingdom: Cambridge University Press.

Pánek, P., Kostura, B., Čepeláková, I., Koutník, I. and Tomšej, T. (2014) 'Pyrolysis of oil sludge with calcium-containing additive', Journal of Analytical and Applied Pyrolysis, 108, pp. 274-283.

Ramaswamy, B., Kar, D. D. and De, S. (2007) 'A study on recovery of oil from sludge containing oil using froth flotation', Journal of Environmental Management, 85(1), pp. $150-154$.

Ramirez, D. and Collins, C. D. (2018) 'Maximisation of oil recovery from an oil-water separator sludge: Influence of type, concentration, and application ratio of surfactants', Waste Management, 82, pp. 100-110.

Ramirez, D. and Dussan, J. (2014) 'Landfarmed oil sludge as a carbon source for Canavalia ensiformis during phytoremediation', International Journal of Environmental Science and Technology, 11(5), pp. 1197-1206.

Roy, A., Dutta, A., Pal, S., Gupta, A., Sarkar, J., Chatterjee, A., Saha, A., Sarkar, P., Sar, P. and Kazy, S. K. (2018) 'Biostimulation and bioaugmentation of native microbial community accelerated bioremediation of oil refinery sludge', Bioresource Technology, 253, pp. 22-32.

Saikia, M. S. B., Bora, M. M. and Dutta, N. N. 2003. Oil recovery from refinery sludge-a case study (Abstract number-CHM 027). CHEMCON-2003 (International Conference of Chemical Control Legislation and Trade Aspects). Singapore. 
Schirmacher, M., Freimann, P., Schmidt, D. and Dahlmann, G. (1993) 'Trace metal determination by total-reflection X-ray fluorescence (TXRF) for the differentiation between pure fuel oil (bunker oil) and waste oil (sludge) in maritime shipping legal cases', Spectrochimica Acta Part B: Atomic Spectroscopy, 48(2), pp. 199-205.

Shaheen, S. M., Tsadilas, C. D., Ok, Y. S. and Rinklebe, J. (2016) 'Potential Mobility, Bioavailability, and Plant Uptake of Toxic Elements in Temporary Flooded Soils', in Rinklebe, J., Knox, A.S. \& Paller, M. (eds.) Trace Elements in Waterlogged Soils and Sediments. Boca Raton, FL, USA: CRC Press: Taylor \& Francis Group.

Shahidi Rizi, M. S., Emtiazi, G., Sepahi, A. A., Beheshti Maal, K. and Hosseini, F. (2017) 'Synergistic effect of nanoparticles and Thalassospira sp. isolated from Bahregan area in biodegradation of oil sludge', Petroleum Science and Technology, 35(9), pp. 831838.

Shelley, S., Stokman, S. K. and Sogorka, B. J. (1997) 'Soil contamination: Dealing with petroleum spills', Chemical Engineering, 104(1), pp. 113.

Shen, L. and Zhang, D.-K. (2003) 'An experimental study of oil recovery from sewage sludge by low-temperature pyrolysis in a fluidised-bed $\varkappa^{\prime}$, Fuel, 82(4), pp. 465-472.

Shen, Y., Chen, X., Wang, J., Ge, X. and Chen, M. (2016) 'Oil sludge recycling by ashcatalyzed pyrolysis-reforming processes', Fuel, 182, pp. 871-878.

Shie, J.-L., Lin, J.-P., Chang, C.-Y., Wu, C.-H., Lee, D.-J., Chang, C.-F. and Chen, Y.-H. (2004) 'Oxidative Thermal Treatment of Oil Sludge at Low Heating Rates', Energy \& Fuels, 18(5), pp. 1272-1281.

Silva, R. C., Carneiro, G. F., Barbosa, L. L., Lacerda, V., Freitas, J. C. C. and de Castro, E. V. R. (2012) 'Studies on crude oil-water biphasic mixtures by low-field NMR', Magnetic Resonance in Chemistry, 50(2), pp. 85-88. 
Simpson, A. J., McNally, D. J. and Simpson, M. J. (2011) 'NMR spectroscopy in environmental research: From molecular interactions to global processes', Progress in Nuclear Magnetic Resonance Spectroscopy, 58(3-4), pp. 97-175.

Sivarao, S., Milkey, K. R., Samsudin, A. R., Dubey, A. K. and Kidd, P. (2014) 'Comparison between Taguchi Method and Response Surface Methodology (RSM) in Modelling $\mathrm{CO}_{2}$ Laser Machining', Jordan Journal of Mechanical \& Industrial Engineering, 8(1), pp. 35-42.

Speight, J. G. (2006) The Chemistry and Technology of Petroleum. Chemical Industries Fourth edn. Laramie, Wyoming, USA: Taylor \& Francis.

Taiwo, E. A. and Otolorin, J. A. (2009) 'Oil Recovery from Petroleum Sludge by Solvent Extraction', Petroleum Science and Technology, 27(8), pp. 836-844.

Trejo, F., Ancheyta, J., Centeno, G. and Marroquín, G. (2005) 'Effect of hydrotreating conditions on Maya asphaltenes composition and structural parameters', Catalysis Today, 109(1), pp. 178-184.

Tsodikov, M. V., Konstantinov, G. I., Chistyakov, A. V., Arapova, O. V. and Perederii, M. A. (2016) 'Utilization of petroleum residues under microwave irradiation', Chemical Engineering Journal, 292, pp. 315-320.

USEPA 2004. How to Evaluate Alternative Cleanup Technologies for Underground Storage Tank Sites: A Guide for Corrective Action Plan Reviewers (EPA 510-R-04-002). US Environmental Protection Agency. Washington, DC, USA.

Uçar, S., Özkan, A. R. and Karagöz, S. (2016) 'Co-pyrolysis of waste polyolefins with waste motor oil', Journal of Analytical and Applied Pyrolysis, 119, pp. 233-241.

Viana, F. F., de Castro Dantas, T. N., Rossi, C. G. F. T., Dantas Neto, A. A. and Silva, M. S. (2015) 'Aged oil sludge solubilization using new microemulsion systems: Design of experiments', Journal of Molecular Liquids, 210, Part A, pp. 44-50. 
775

776

777

778

779

780

781

782

783

784

785

786

787

788

789

790

791

792

793

794

795

796

797

798

799

Villalanti, D. C., Raia, J. C. and Maynard, J. B. (2006) 'High-temperature Simulated Distillation Applications in Petroleum Characterization', in Meyers, R.A. (ed.) Encyclopedia of Analytical Chemistry. Hoboken, NJ, USA: John Wiley and Sons, Ltd.

Wang, J., Han, X., Huang, Q., Ma, Z., Chi, Y. and Yan, J. (2018) 'Characterization and migration of oil and solids in oily sludge during centrifugation', Environmental Technology, 39(10), pp. 1350-1358.

Wang, J., Yin, J., Ge, L., Shao, J. and Zheng, J. (2010) 'Characterization of Oil Sludges from Two Oil Fields in China', Energy and Fuels, 24(2), pp. 973-978.

Wang, S., Wang, X., Zhang, C., Li, F. and Guo, G. (2016) 'Bioremediation of oil sludge contaminated soil by landfarming with added cotton stalks', International Biodeterioration \& Biodegradation, 106, pp. 150-156.

Ward, O., Singh, A. and Van Hamme, J. (2003) 'Accelerated biodegradation of petroleum hydrocarbon waste', Journal of Industrial Microbiology and Biotechnology, 30(5), pp. $260-270$.

Yang, L., Nakhla, G. and Bassi, A. (2005) 'Electro-kinetic dewatering of oily sludges', Journal of Hazardous Materials, 125(1-3), pp. 130-140.

Zhang, J., Li, J., Thring, R. W., Hu, X. and Song, X. (2012) 'Oil recovery from refinery oily sludge via ultrasound and freeze/thaw', Journal of Hazardous Materials, 203-204, pp. 195-203.

Zhang, Y., Zhao, H., Shi, Q., Chung, K. H., Zhao, S. and Xu, C. (2011) 'Molecular Investigation of Crude Oil Sludge from an Electric Dehydrator', Energy \& Fuels, 25(7), pp. 31163124.

Zhao, S., Zhou, X., Wang, C. and Jia, H. (2017) 'Dewatering and low-temperature pyrolysis of oily sludge in the presence of various agricultural biomasses', Environmental Technology, pp. 1-9. 
800 Zheng, C., Wang, M., Wang, Y. and Huang, Z. (2012) 'Optimization of biosurfactant-mediated 801 oil extraction from oil sludge', Bioresource Technology, 110, pp. 338-342.

802 Zheng, X., Jin, Y., Chi, Y. and Ni, M. (2013) 'Simultaneous Determination of Water and Oil 803 in Oil Sludge by Low-Field 1H NMR Relaxometry and Chemometrics', Energy \& $804 \quad$ Fuels, 27(10), pp. 5787-5792.

805 Zubaidy, E. A. H. and Abouelnasr, D. M. (2010) 'Fuel recovery from waste oily sludge using 806 solvent extraction', Process Safety and Environmental Protection, 88(5), pp. 318-326.

807

808 

of the oil sludges.

\begin{tabular}{|c|c|c|c|c|}
\hline Element & WSS & ODS & STS & $\mathbf{R S}$ \\
\hline $\mathrm{Al}$ & $1,455( \pm 9)$ & $506( \pm 20)$ & $104( \pm 3)$ & $116( \pm 1)$ \\
\hline $\mathrm{As}^{*}$ & $2( \pm 0.24)$ & $1( \pm 0.11)$ & $0.10( \pm 0.03)$ & $0.13( \pm 0.09)$ \\
\hline $\mathrm{Ba}$ & $131( \pm 7)$ & $85( \pm 13)$ & $40( \pm 2)$ & $41( \pm 5)$ \\
\hline $\mathrm{Ca}$ & $5,811( \pm 44)$ & $4,369( \pm 2505)$ & $5,260( \pm 3033)$ & $11,093( \pm 160)$ \\
\hline $\mathrm{Cd}^{*}$ & $1( \pm 0.02)$ & $0.08( \pm 0.01)$ & $0.02( \pm 0.01)$ & $0.02( \pm 0.01)$ \\
\hline $\mathrm{Co}^{*}$ & $7( \pm 0.18)$ & $0.27( \pm 0.02)$ & $0.66( \pm 0.01)$ & $0.21( \pm 0.01)$ \\
\hline $\mathrm{Cr}^{*}$ & $85( \pm 0.44)$ & $2( \pm 0.19)$ & $9( \pm 0.30)$ & $9( \pm 0.07)$ \\
\hline $\mathrm{Cu}^{*}$ & $142( \pm 3)$ & $8( \pm 0.08)$ & $7( \pm 0.20)$ & $12( \pm 0.80)$ \\
\hline $\mathrm{Fe}$ & $5,912( \pm 26)$ & $1,536( \pm 867)$ & $16,146( \pm 252)$ & $13,915( \pm 278)$ \\
\hline $\mathrm{K}$ & $436( \pm 12)$ & $85( \pm 3)$ & $81( \pm 5)$ & $116( \pm 6)$ \\
\hline $\mathrm{Li}$ & $2( \pm 0.01)$ & $0.80( \pm 0.01)$ & $0.65( \pm 0.05)$ & $0.86( \pm 0.03)$ \\
\hline $\mathrm{Mg}$ & $502( \pm 5)$ & $220( \pm 10)$ & $235( \pm 3)$ & $276( \pm 9)$ \\
\hline $\mathrm{Mn}$ & $142( \pm 3)$ & $179( \pm 3)$ & $23( \pm 0.47)$ & $21( \pm 0.41)$ \\
\hline $\mathrm{Na}$ & $869( \pm 21)$ & $65( \pm 17)$ & $168( \pm 16)$ & $241( \pm 3)$ \\
\hline $\mathrm{Ni}^{*}$ & $85( \pm 0.58)$ & $2( \pm 0.23)$ & $2( \pm 0.14)$ & $2( \pm 0.35)$ \\
\hline $\mathrm{Pb}^{*}$ & $101( \pm 0.46)$ & $45( \pm 2)$ & $9( \pm 0.93)$ & $9( \pm 2)$ \\
\hline $\mathrm{Sr}$ & $35( \pm 0.33)$ & $93( \pm 6)$ & $6( \pm 0.24)$ & $7( \pm 0.07)$ \\
\hline $\mathrm{Zn}^{*}$ & $376( \pm 7)$ & $1,683( \pm 22)$ & $3,074( \pm 1814)$ & $6,336( \pm 85)$ \\
\hline
\end{tabular}

$812 *$ These elements are potentially toxic elements (PTEs) (Shaheen et al., 2016).

813 Values in bold are over the limit of the acceptable standards of landfilling of hazardous waste established by the European Union: As (25

$814 \mu \mathrm{g} \cdot \mathrm{g}^{-1}$ ), $\mathrm{Cd}$ (5), $\mathrm{Cr}$ (70), $\mathrm{Cu}(100), \mathrm{Ni}(40), \mathrm{Pb}(50), \mathrm{Zn}$ (200) (Kriipsalu et al., 2008). The mean values with the standard deviation (in 815 parentheses) are shown $(n=3)$. 


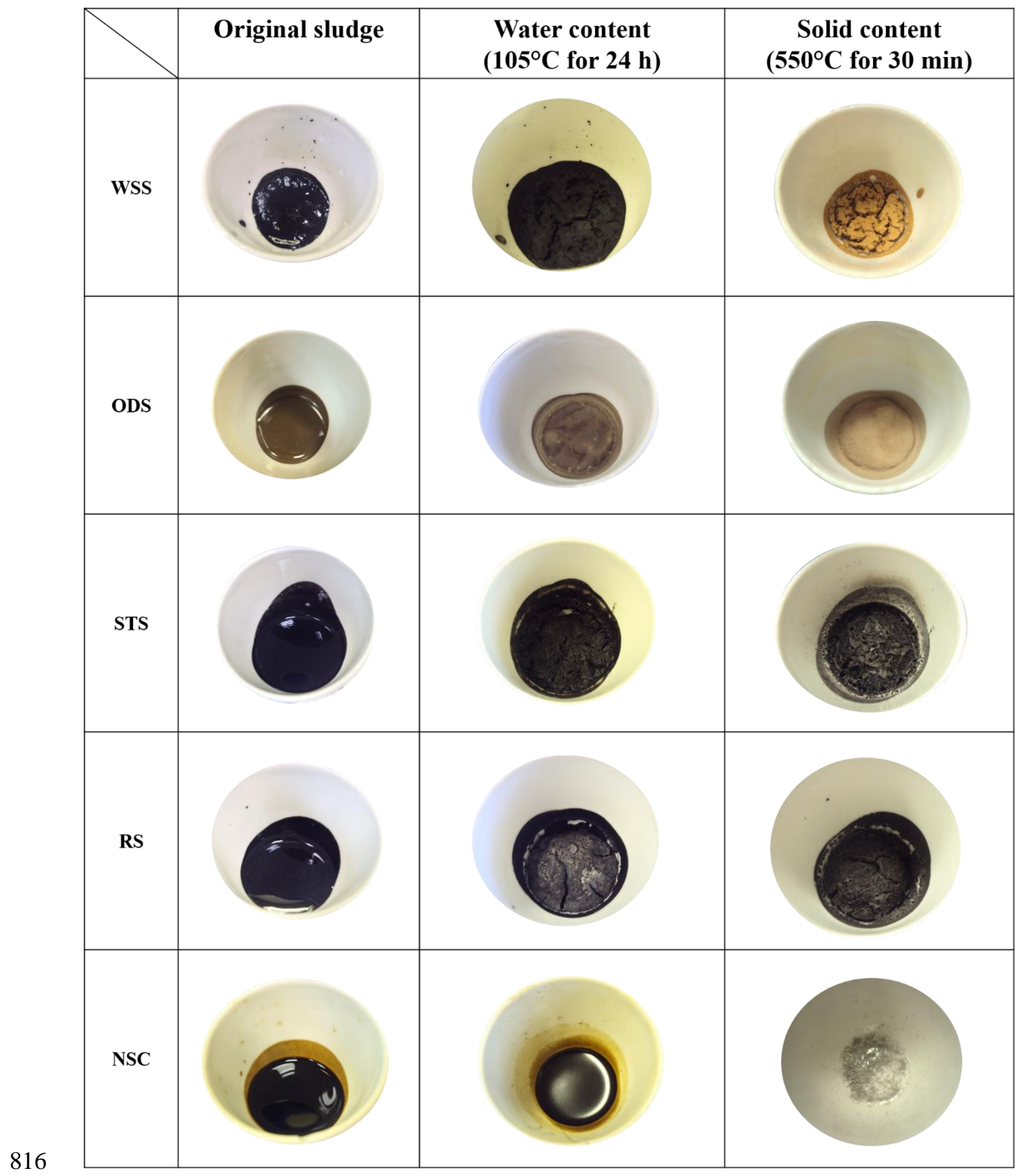

Figure S 1. Oil sludge samples before, after heating at $105^{\circ} \mathrm{C}$ for $24 \mathrm{~h}$ 818 (water content) and $550^{\circ} \mathrm{C}$ for $30 \mathrm{~min}$ using the oven-drying method. 


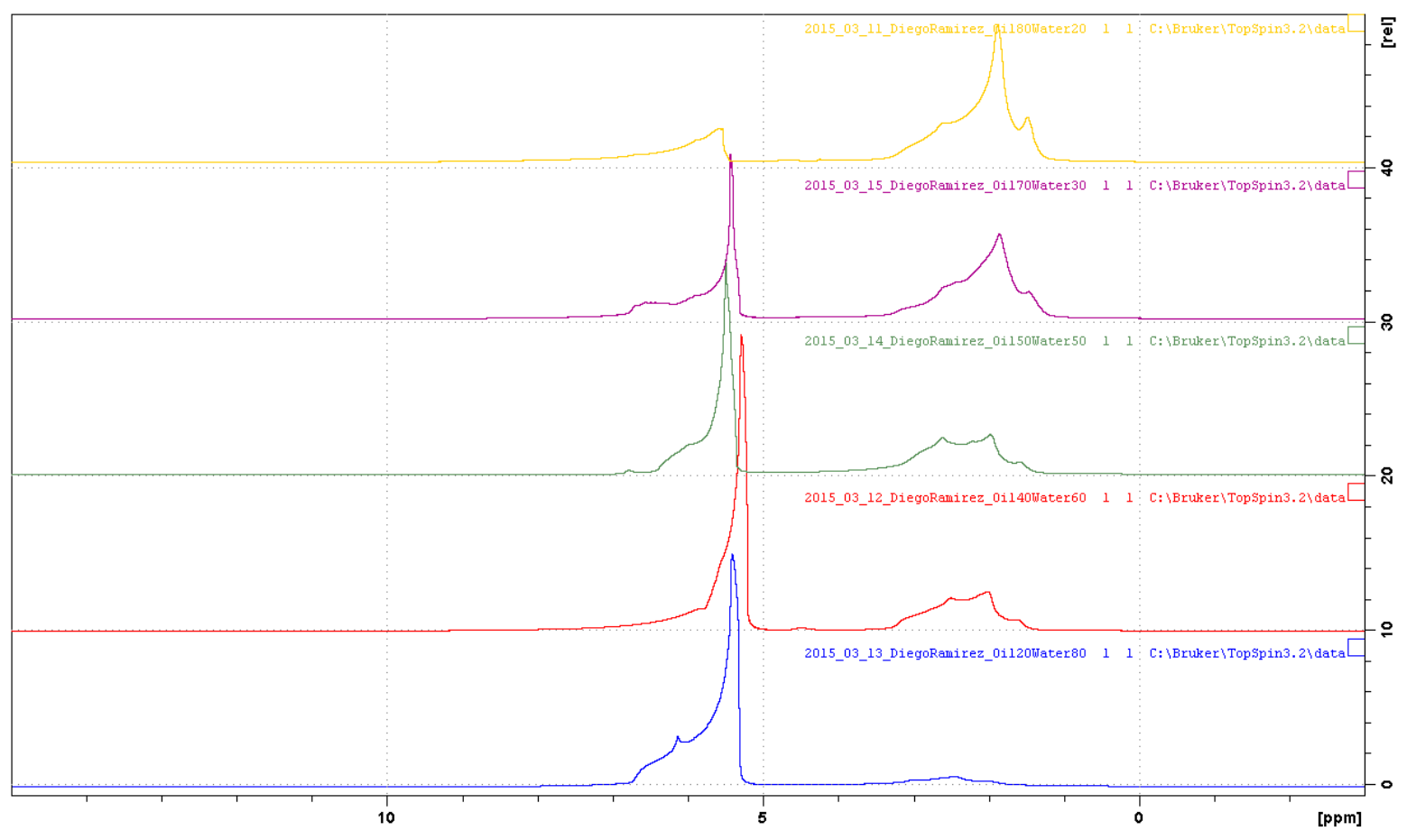

Figure S 2. ${ }^{1} \mathrm{H}$ spectra of the oil and water mixtures standards. From top to bottom: oil $80 \%$ + water $20 \%$, oil $70 \%$ + water $30 \%$, oil $50 \%$ + water $50 \%$, oil $40 \%$ + water $60 \%$, and oil $20 \%$ + water $80 \%$. 


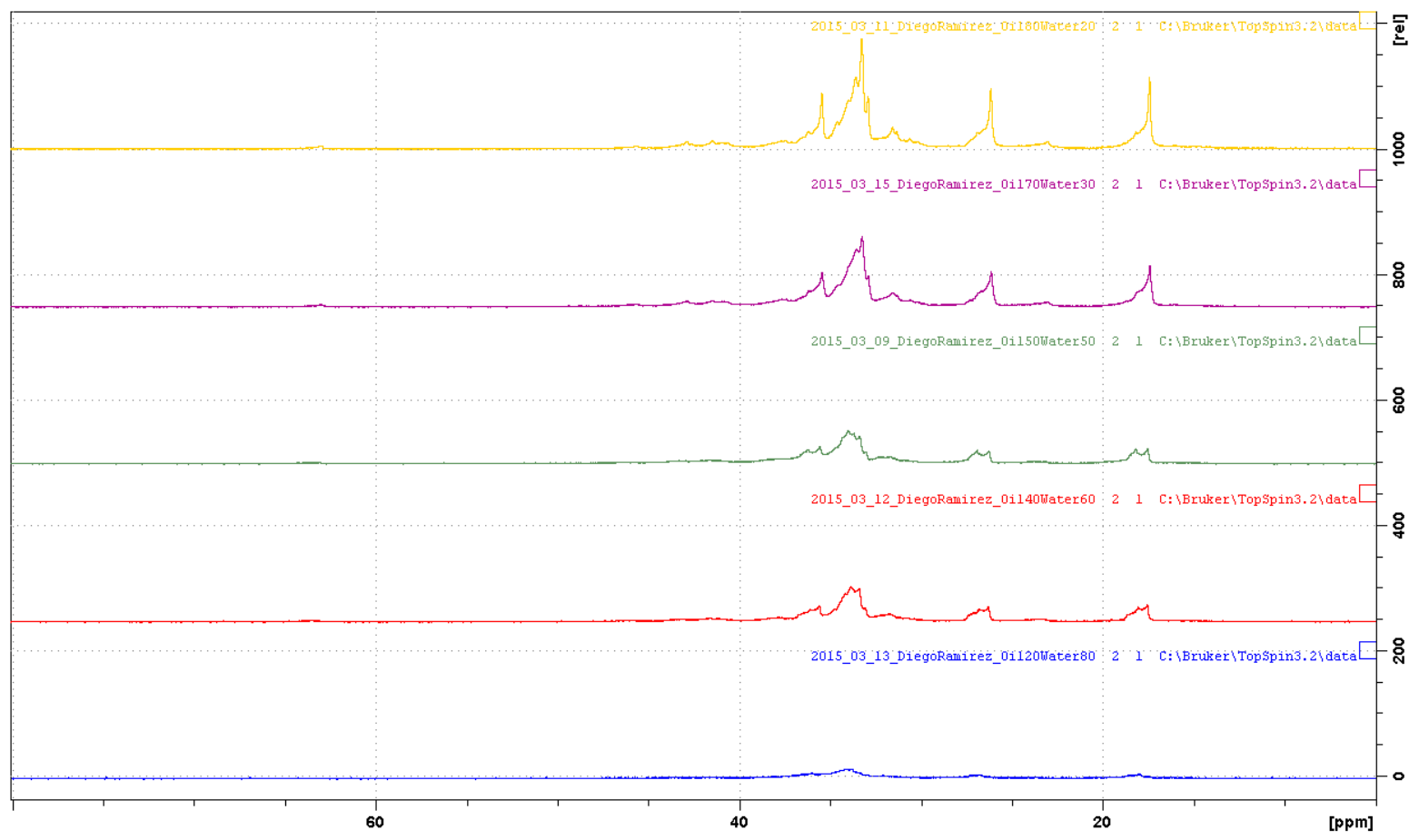

Figure S 3. ${ }^{13} \mathrm{C}$ spectra of the oil and water mixtures standards. From top to bottom: oil $80 \%$ + water $20 \%$, oil $70 \%$ + water $30 \%$, oil $50 \%$ + water $50 \%$, oil $40 \%$ + water $60 \%$, and oil $20 \%$ + water $80 \%$. 


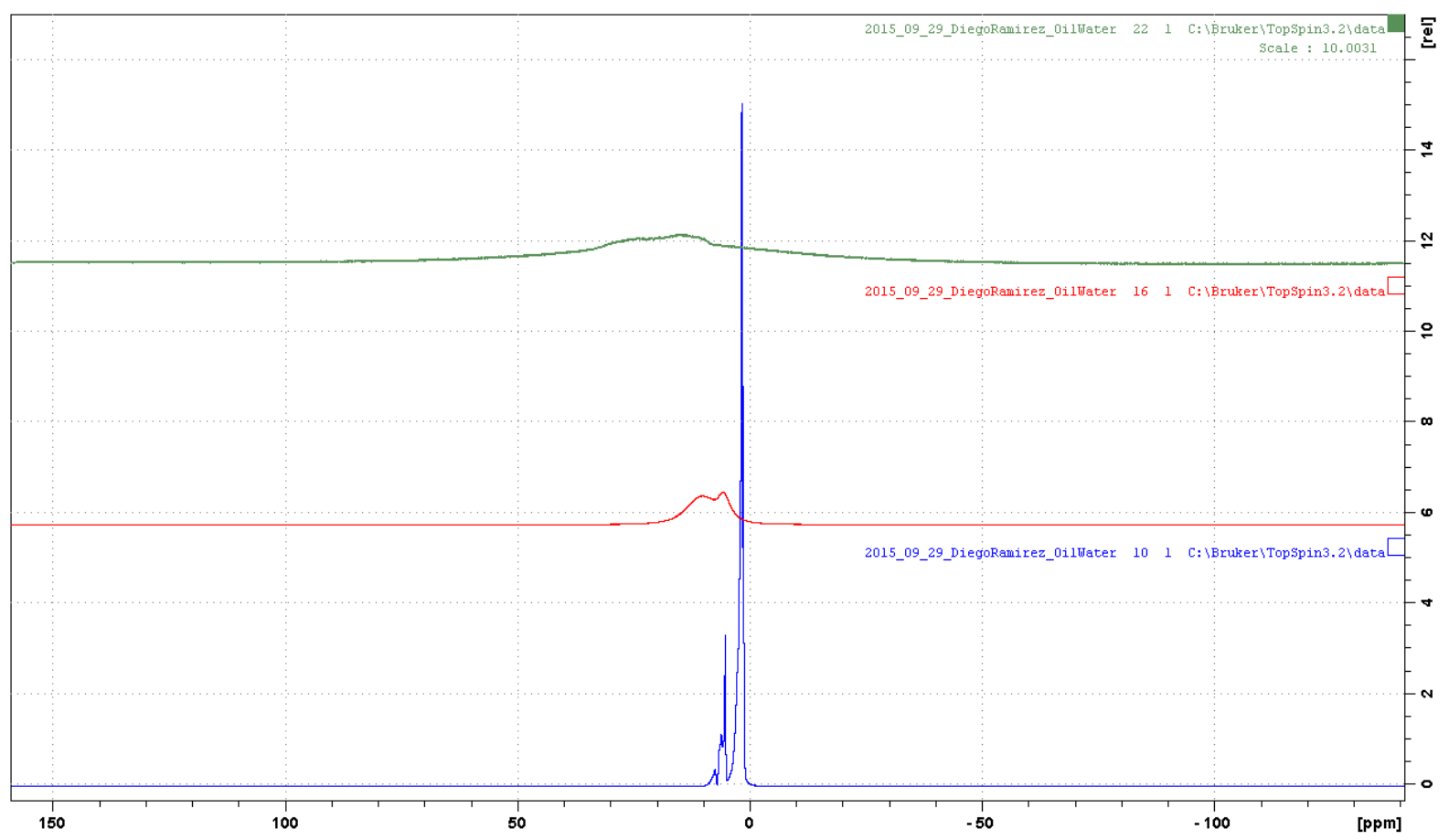

Figure S 4. 1D spectra of the sludges. From top to bottom: ODS, RS and NSC. 

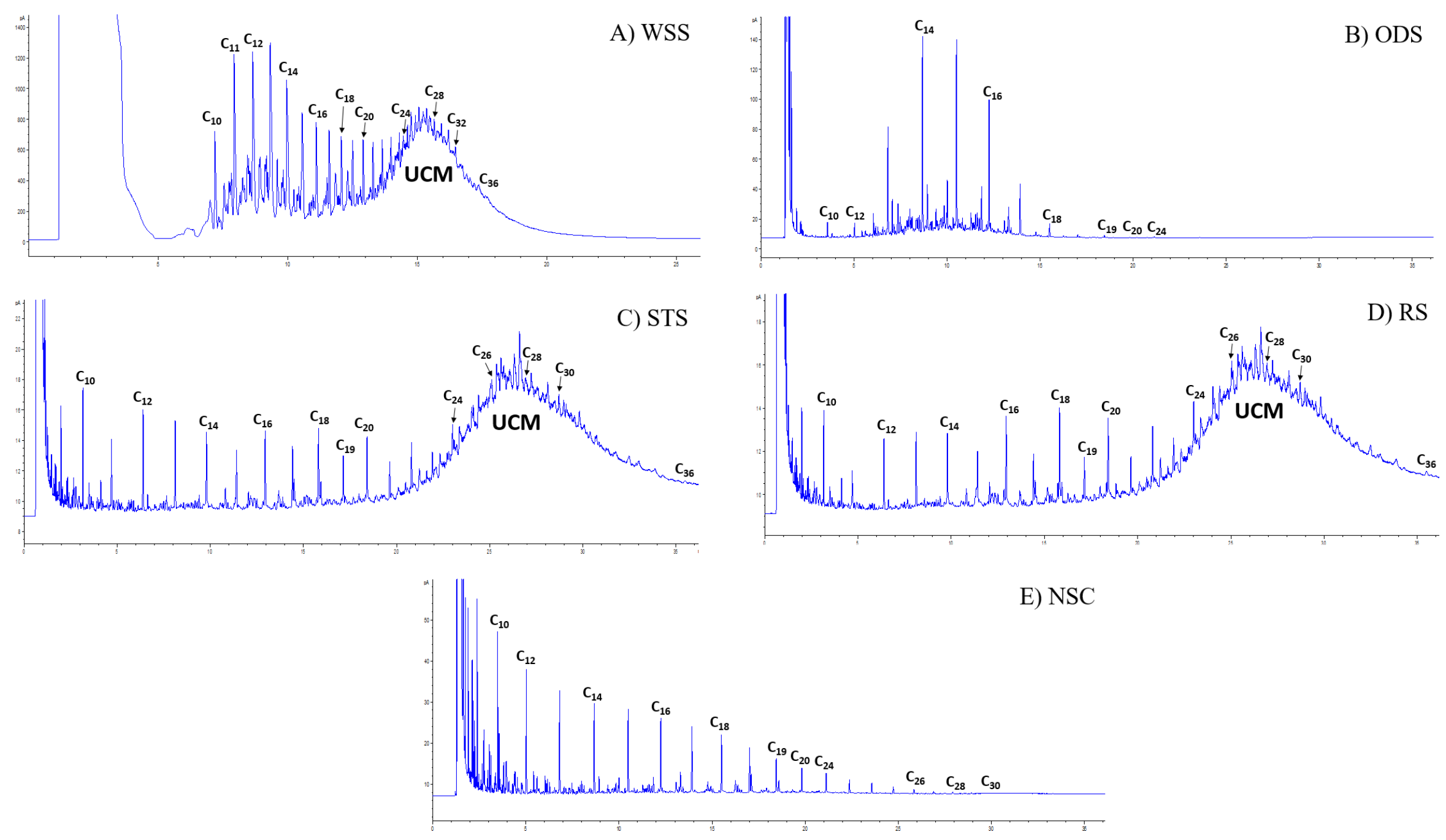

Figure S 5. Gas chromatograms of the EPH aliphatic compounds for all the analysed oil sludges. The retention times (min) are shown on the x-axis. The signal magnitude of the peaks was pA (picoamps; y-axis). The unresolved complex mixtures (UCM) are indicated. 
